
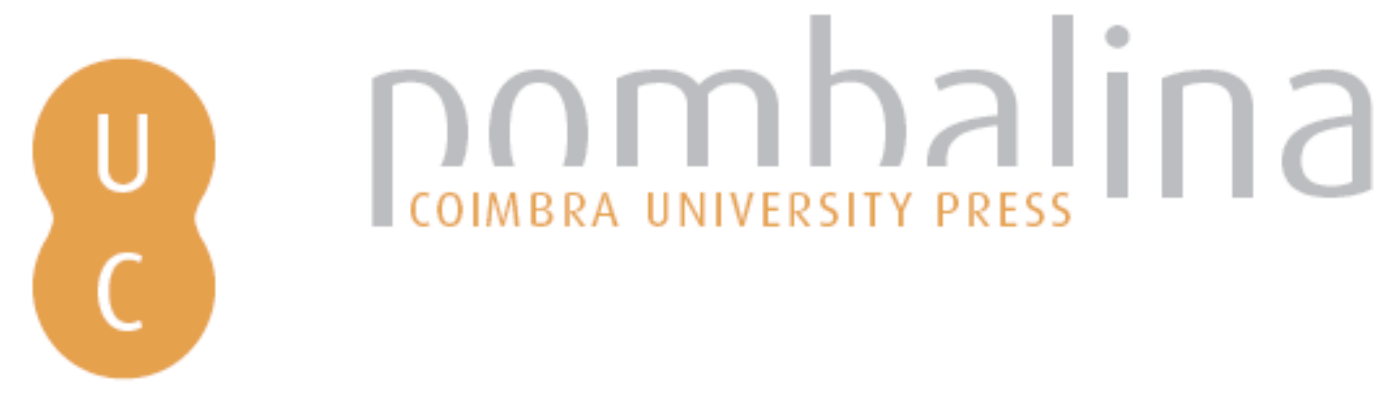

\title{
Nomos e Kosmos na caracterização do António e da Cleópatra de Plutarco
}

\author{
Autor(es): $\quad$ Rodrigues, Nuno Simões
}

Publicado por: Imprensa da Universidade de Coimbra

URL

persistente: URI:http://hdl.handle.net/10316.2/32876

DOI: $\quad$ DOI:http://dx.doi.org/10.14195/978-989-721-012-9_7

Accessed : $\quad$ 26-Apr-2023 15:58:37

A navegação consulta e descarregamento dos títulos inseridos nas Bibliotecas Digitais UC Digitalis, UC Pombalina e UC Impactum, pressupõem a aceitação plena e sem reservas dos Termos e Condições de Uso destas Bibliotecas Digitais, disponíveis em https://digitalis.uc.pt/pt-pt/termos.

Conforme exposto nos referidos Termos e Condições de Uso, o descarregamento de títulos de acesso restrito requer uma licença válida de autorização devendo o utilizador aceder ao(s) documento(s) a partir de um endereço de IP da instituição detentora da supramencionada licença.

Ao utilizador é apenas permitido o descarregamento para uso pessoal, pelo que o emprego do(s) título(s) descarregado(s) para outro fim, designadamente comercial, carece de autorização do respetivo autor ou editor da obra.

Na medida em que todas as obras da UC Digitalis se encontram protegidas pelo Código do Direito de Autor e Direitos Conexos e demais legislação aplicável, toda a cópia, parcial ou total, deste documento, nos casos em que é legalmente admitida, deverá conter ou fazer-se acompanhar por este aviso.

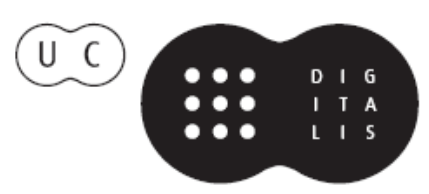




\section{Nomos, Kosmos \& Dike in Plutarch}

José Ribeiro Ferreira, Delfim F. Leão \& Carlos A. Martins de Jesus (eds.) 


\title{
Nomos E Kosmos Na CARACTERIZAÇÃo do ANTÓNIO E DA Cleópatra de Plutarco
}

\author{
Nuno Simões Rodrigues \\ Universidade de Lisboa
}

\begin{abstract}
Although words like nomos and kosmos are almost absent in Plutarch's biography of Antony and Cleopatra, the concepts they imply support the author's construction of the Life. The "bigamist" relationship between Antony, Octavia and Cleopatra as well as Antony's uncontrollable passion for Cleopatra are examples of the absence of law and order in Mark Antony's life.
\end{abstract}

As palavras gregas que definem "lei"1 e "ordem" estão praticamente ausentes do relato plutarquiano da relação de António com Cleópatra. Referimo-nos à Vita Antonii (36.7), na qual, ainda assim, se verificam excepções, como a forma nomous, que ocorre como referência às leis de Sólon, numa metonímia que pretende aludir à condenação do adultério em Atenas. Como nota C. Pelling 1994: 220, esta referência evoca um debate presente nos séculos IV e V a.C., quando alguns heróis foram idealizados por seguirem a sua physis ignorando os nomoi humanos artificiais. O próprio Plutarco refere essas leis, na Vita Solonis (22.4), assinalando que tais normas negavam os direitos paternos em relação aos filhos nascidos fora do casamento legítimo3. Outra excepção é o uso do termo kosmos no passo em que se faz a apresentação de Cleópatra, mas com o sentido de "adorno", que a rainha teria usado para se preparar para o encontro com António, em Tarso (Ant.25.6).

Este dado não significa, porém, que os conceitos ou ideias a ele associadas, não estejam presentes no espírito e, por conseguinte, na narrativa de Plutarco, quando compõe a vida de Marco António e, em particular, descreve a relação do tribuno com a última rainha do Egipto lágida. Em suma: que essas noções façam parte da mensagem que o autor grego pretende cunhar nas representações das personagens que caracteriza neste contexto.

Para percebermos o alcance do texto plutarquiano, há que ter presentes os dados em jogo, designadamente: a união de António a Cleópatra; o casamento do romano com Octávia, irmã de Octávio; e ainda a relação entre os dois generais, bem como as repercussões que teve na política romana da segunda metade do século I a.C.

Em 40 a.C., António casou-se com Octávia, com o objectivo de firmar o

\footnotetext{
${ }^{1}$ Nomos, que segundo A. BAIlly 1950: 1332, pode também significar “costume” ou "regra".

${ }^{2}$ Kosmos, que segundo A. BAilly 1950: 1125, pode também significar "o que é conveniente ou adequado", "disciplina" ou "organização". A problemática em torno da semântica destes termos é desenvolvida no texto de Carlos A. Martins de Jesus, neste mesmo volume.

${ }^{3}$ Ver o comentário em D. F. LEÃo 1999: 96, n. 71.
} 
tratado de Brundísio, que dividia os territórios controlados por Roma: Octávio passava a controlar o Mediterrâneo ocidental, enquanto António controlaria o oriental ${ }^{4}$. Há ainda que ter presente que o acordo de Brundísio vinha na sequência do assassinato de Júlio César em 44 a.C. e da guerra civil que entretanto eclodira em Roma e que opusera a facção republicana à cesarista.

O casamento de conveniência celebrado entre António e a irmã de Octávio fora favorecido pelo facto de o primeiro ter enviuvado de Fúlvia, nesse mesmo ano de 40 a.C., sendo que esta tivera um papel importante nas lutas políticas que se sucederam à morte de César e das quais o próprio Plutarco dá testemunho (Ant. 10.5-10; 28.1; 30.1-6; 31.3). Mas em 41 a.C., António encontrara-se com Cleópatra VII do Egipto em Tarso, na Cilícia, numa reunião que motivou a Plutarco algumas das mais belas páginas da sua obra (Ant.25-28). A relação encetada com a macedónia foi interrompida pelo casamento celebrado com Octávia, o qual terá por certo seguido as normas romanas que legitimavam uma união desta natureza perante a ordem social. As circunstâncias e o estatuto dos nubentes exigiam-no. Mas em 37 a.C., o tribuno romano reencetou os contactos com Cleópatra, ao regressar ao Oriente, com o objectivo, entre outros, de combater os Partos. Na verdade, acima de tudo, e não negando quaisquer eventuais factores emotivos (porque esses escapam mais facilmente ao historiador), a relação de António com Cleópatra baseava-se numa componente política substancial: com esta ligação, a rainha do Egipto assegurava o trono enquanto o general romano ficava com recursos significativos à sua disposição para controlar todo o Oriente mediterrâneo e, por conseguinte, fortalecer a sua posição em Roma.

Os acontecimentos, todavia, não se revelaram como António esperava. A campanha de 36 contra os Partos foi um desaire e a saída de Emílio Lépido do triunvirato pouco depois conduziram ao aumento da rivalidade entre Octávio e António. A partir de 34, António instala-se em Alexandria e assume-se qual monarca de tipo oriental. Na base da construção dessa nova imagem está, como é evidente, o apoio de Cleópatra. $\mathrm{O}$ casal comporta-se agora como tal, sendo que Marco António transforma as regiões orientais em reinos que distribui pela rainha lágida e seus filhos, três dos quais nascidos já da relação com o tribuno romano.

Em 32 a.C., António divorcia-se de Octávia, num processo tacitamente

${ }^{4}$ A importância de Octávia neste processo político pode averiguar-se por Plu. Ant. 35.

${ }^{5}$ Sobre esta questão, ver C. Pelling 1994: 202, e S. Treggiari 2002. As diligências legais referidas por Plu. Ant. 31.5 sugerem que tudo terá sido tratado com o maior cuidado legal. Certamente um casamento in manum, eventualmente na forma de confarreatio. Na verdade, as vicissitudes de Octávia aquando da separação de António, bem como a forma como Octávio agiu em relação à irmã, levam-nos a tratar estas questões com cautela, nomeadamente se a forma de casamento teria sido cum manu ou sine manu. Octávia começou por se recusar a abandonar a casa do marido, quando o irmão lho pediu. Vd. S. Treggiari, 2002: 468-469. 
desejado por Octávio, que ao mesmo tempo reúne argumentos para declarar guerra a Cleópatra. Mas o seu principal objectivo é, naturalmente, afastar de vez a concorrência de António ao poder em Roma. A batalha de Áccio no ano seguinte, em 31 a.C., abriu caminho para a invasão romana do Egipto, no ano seguinte, marcada pelos suicídios de António e Cleópatra.

O que nos interessa destacar neste processo, de modo a salientar os conceitos de nomos e kosmos, atem-se precisamente à relação dúbia que se estabeleceu entre o tribuno romano e a rainha do Egipto no período em que durou o casamento daquele com Octávia. Como assinalámos, as diligências tomadas aquando da união de António com a irmã de Octávio levam a crer que o matrimónio então celebrado se terá pautado pelas regras que faziam do casamento romano um consórcio legítimo, i.e., de acordo com o nomos, pois só desse modo teriam todos os seus derivados (heranças e transmissão de propriedade, descendência, e até mesmo o exercício do poder) sido igualmente legítimos (vd. Ant. 54.1). De outra forma, essa teria decerto sido uma união desacreditada e por conseguinte politicamente nula.

Já o processo de divórcio, habilmente usado por Octávio nas suas pretensões políticas, não terá sido pacífico, inclusive por mercê da resistência de Octávia a separar-se do marido (vd. Ant. 54.1) ${ }^{6}$. O facto é que a atitude de Octávio para com a irmã denuncia também o ultraje de que ela fora alvo e que foi publicamente reconhecido. O divórcio de António e Octávia terá dado, aliás, que falar entre os Romanos, como se depreende da anedota transmitida por Séneca-o-Velho nas Suasoriae. Conta-se que, precisamente porque se achava casado com Octávia ao mesmo tempo que coabitava com Cleópatra, alguém em Roma terá escrito na base de uma estátua que o representava: "Octávia e Atena para António; e leva o que é teu" (Sen. Suas. 1.6)7.

Esta nota indica que, entre os Romanos, se considerava a união de António e Cleópatra, pelo menos, ilegítima. Na mesma linha discursiva e a julgar pelas informações dadas por Plutarco, quando em 37 a.C. António voltou ao Oriente, a paixão (sintomaticamente, Plutarco usa eros) por Cleópatra, que parecia adormecida e "enfraquecida pela presença de melhores influências", reacendeuse de forma violentíssima, acabando por levar à vivência comum, marital mesmo, de ambos, à qual decerto, frisamos, não terá sido estranha uma forte motivação política (Plu. Ant. 36.1). Plutarco chega mesmo a evocar a célebre metáfora do Fedro de Platão, para descrever o que acontecera com António por

\footnotetext{
${ }^{6}$ Cf. C. Pelling 1994: 248.
}

${ }^{7}$ Trata-se de uma frase escrita em grego (Oktaouia kai Athena Antonioi) e em latim (res tuas tibi habe), correspondendo esta segunda parte à fórmula do divórcio romano. $\mathrm{O}$ cônjuge que desejava o divórcio informava o outro, oralmente, por escrito ou por um mensageiro, de que devia recolher os seus bens pessoais e abandonar o domicílio comum. Ver S. Treggiari 2002: 446-448. 
causa da rainha oriental ${ }^{8}$. Mas essa ilegitimidade, que na perspectiva romana terá sido uma anomia, não seria coincidente com o que então se vivia na cidade de Alexandria. Com efeito, muito provavelmente, na perspectiva oriental, essa mesma relação seria entendida como um casamento. Parece-nos evidente que, na perspectiva romana, não se trataria de tal. Apesar de numa carta transcrita por Suetónio na Vita diui Augusti, António parecer referir-se a Cleópatra como sua $u x o r^{9}$, o próprio Plutarco afirma que embora o romano não negasse as suas relações com a "egípcia", "não se considerava casado" (Ant. 31.3). Mas o facto é que, segundo as descrições plutarquianas, António coabitaria com Cleópatra como se fosse seu marido e as alegorias hierogâmicas que na biogria plutarquiana associam os pares divinos Dioniso/ Afrodite e Osíris/ Ísis ao casal parecem vir em abono dessa tese ${ }^{10}$. E se perspectivarmos a relação pela óptica oriental, a mesma seria muito certamente entendida como um casamento, uma vez que, no Egipto, o matrimónio não parece ter sido assinalado por qualquer tipo de cerimónia civil ou religiosa, mas antes por um mútuo consentimento entre as partes envolvidas a que se associava a coabitação ${ }^{11}$. Não excluímos, porém, a hipótese de a natureza desta relação estar próxima do que em Roma se entendia por casamento por usus, ainda que o mesmo não fosse adequado a indivíduos do estatuto social de António e Cleópatra. C. Pelling 1994: 219 chega mesmo a afirmar que "se António não fosse casado e se ambos fossem de um estatuto social inferior, até mesmo os Romanos os teriam entendido como casados" ${ }^{12}$.

Também na síncrese que avalia o par Demétrio/António, Plutarco refere que o tribuno romano estivera "casado com duas mulheres ao mesmo tempo, aquilo a que nunca antes nenhum romano se atrevera" (Ant.91(4).2). Aparentemente, o que Plutarco faz neste passo é assumir a posição orientalista da questão, porque convém ao seu objectivo (construir uma imagem negativa de António) e porque, como também afirma o mesmo Plutarco, "apesar da relação com Cleópatra, António não se considerava casado com ela” (Ant. 31.3), tal como estipulava a lei romana. E num outro passo, o biógrafo afirma que "Octávia se unira a António por questões políticas, por causa do irmão, desfrutando assim do título de esposa (to tes gametes onoma karpousthai), ao passo que Cleópatra, rainha de tantos súbditos, era chamada de amante

${ }^{8}$ Trata-se da famosa metáfora do cavalo da alma: P1. Phdr. 254a.

${ }^{9}$ Suet. Aug. 69.2: quid te mutauit? Quod reginam ineo? Vxor mea est. A interpretação do passo, porém, não é pacífica, pois algumas lições lêem uma interrogativa, uxor mea est?, o que altera o sentido do texto, e não uxor mea est. Esta fonte é portanto problemática nesta questão.

${ }^{10}$ Vd. Plu. Ant. 26; 71-85. Cf. F. E. Brenk 1992b: 159-182; N. S. Rodrigues 2002.

${ }^{11}$ P.W. Pestman 1961: 6-52. Trata-se de algo semelhante ao que em Roma se entendia por casamento por usus.

${ }^{12}$ Cf. D. C. Braund 1984: 179-180. 
de António (eromenen kaleisthai), não rejeitando tal designação ou sequer achando-a indigna" (Ant. 53.9-10). Como foi já notado, parece estar-se aqui perante a dialéctica entre a amica e a uxor, que aparece igualmente na poesia elegíaca romana, sendo que Cleópatra insinua a primeira enquanto Octávia representa a segunda ${ }^{13}$.

Como complemento, podemos citar ainda a Eneida, em que, como se tem salientado, a figura de Dido parece ter sido decalcada de Cleópatra ${ }^{14}$. É por isso sintomático que, no poema, Vergílio represente a rainha oriental como acreditando estar casada com Eneias, enquanto o herói troiano nega tal relação ${ }^{15}$. Por outro lado, e numa contradição já familiar, num passo adiante, o poeta chega ao ponto de chamar a Cleópatra Aegyptia coniunx, a "esposa egípcia" (Aen. 8.688).

Seja como for, a união de António a Cleópatra, quer pelo estatuto dos indivíduos nela implicados quer pelas características da figura feminina, em particular o facto de ser uma estrangeira, dificilmente teria sido entendida como legítima nos vários círculos sociais romanos, incluindo as elites, e, como tal, considerada algo à margem do nomos. Com a agravante de que António era uma importante figura do Estado. Terá sido precisamente esse factor a contribuir para a elaboração de um processo propagandístico, que veio a beneficiar Octávio, no qual a definição das personae non gratae se fez com base na imagem de caos político-social desencadeado pelos protagonistas do episódio, i.e., uma ausência de kosmos que radica nos actos e posições políticas de António e Cleópatra. Por esta ordem de ideias, a consequência dessa ausência de ordem ou akosmia teria sido a guerra, que desembocou em Áccio, na derrota dos da "vida inimitável” (Ant.28.2) e na conquista do Egipto. Que essa ideia dominava os espíritos coevos pode ser atestado pelo termo que Vergílio usa na écfrase do canto VIII da Eneida para se referir a Cleópatra: nefas, i.e., "sacrilégio", "abominação" ou "aquilo que é proibido por lei divina" (Aen. 8.688). Em contrapartida, quando em 30 a.C. o Egipto se transformou em província romana, foi como se a ordem ou kosmos regressasse ao mundo tal como era então percebido e, uma vez, mais graças à pax romana.

Pela forma como escreve a biografia de António, Plutarco parece manter estas ideias subentendidas. Um dos argumentos que podemos trazer à colação para o confirmar é a forma "simpática" e "positiva" com que trata a figura de Octávia, por oposição à forma "antipática” e "negativa” com que constrói o

\footnotetext{
${ }^{13}$ C. Pelling 1994: 247.

${ }^{14}$ Sobre esta problemática, ver M. H. Rocha Pereira ${ }^{3} 2002: 260$; J. Griffin 1999: 194; C. Pelling 1994: 220.

${ }^{15}$ Verg.Aen. 4.125-126,172, 338-339, em que Eneias afirma: "nunca empunhei as tochas de noivo ou cheguei a tais compromissos".
} 
carácter de Cleópatra VII ${ }^{16}$. A própria tragédia de António, que se desenvolve ao longo desta biografia, parece ser fortemente determinada por essa mesma ausência de ordem, de que Cleópatra é uma das principais causas ${ }^{17}$.

Tal akosmia é reevocada de forma exemplar no final da $V i t a$, num passo que contrasta precisamente com aquele que introduz a rainha e que citámos no início deste estudo como uma dos poucos casos em que, no contexto em causa, Plutarco usa o termo kosmos (Ant. 25.6). Trata-se do parágrafo 83, no qual se conta que, após a morte de António, Octávio visitou Cleópatra com intenção de a consolar. Como em quase toda esta biografia, a narrativa é uma vez mais teatral, intensamente dramática. Diz Plutarco que o general romano a encontrou "deitada no chão e que ele, ao vê-lo, correu para ela, usando apenas uma túnica, lançando-se-lhe aos pés, com a cabeça e o rosto terrivelmente desalinhados" (Ant. 83.1). Estamos perante uma metáfora do caos que tomara conta do destino da última rainha do Egipto e que contrasta na perfeição com o kosmos que a caracteriza aquando da sua entrada em cena.

\footnotetext{
${ }^{16}$ Cf. C. Pelling 1994: 219.

${ }^{17}$ Sobre António como figura intensamente dramática, ver F. E. BREn K 1992ª 4347-4469.
} 


\section{Bibliografia}

Bailly, A., Dictionnaire Grec-Français, Paris, 1950.

Braund, D. C., Rome and the Friendly King: the Character of Client Kingship, London, 1984.

Brenk, F. E., "Plutarch's Life "Markos Antonios": a Literary and Cultural Study", $A N R W$ II.33.6, 1992a: 4347-4469.

Brenk, F. E., "Antony-Osiris, Cleopatra-Isis: the End of Plutarch's Antony", in P. A. Stadter (ed.), Plutarch and the Historical Tradition, London-New York, 1992b: 159-182.

Griffin, J., Latin Poets and Roman Life, London, 1999.

LeÃo, D. F., Plutarco, Vida de Sólon, Lisboa, 1999.

Pelling, C. B. R., Plutarch, Life of Antony, Cambridge, 1994.

Pestman, P. W., Marriage and Matrimonial Property in Ancient Egypt: a Contribution to establishing the Legal position of the woman, Leiden, 1961.

Rocha Pereira, M. H., Estudos de História da Cultura Clássica II - Cultura Romana, Lisboa, ${ }^{3} 2002$.

Rodrigues, N. S., "Plutarco, historiador dos Lágidas: o caso de Cleópatra VII Filopator", in J. Ribeiro Ferreira (coord.), Actas do Congresso "Plutarco educador da Europa», Porto, 2002: 127-149.

Treggiari, S., Roman Marriage. "Iusti Coniuges» from the time of Cicero to the time of Ulpian, Oxford, 2002. 